\title{
MODIFICAÇÃO QUÍMICA DO POLIPROPILENO ATRAVÉS DA INTRODUÇÃO DE GRUPOS SULFÔNICOS PARA APLICAÇÃO COMO CATALISADOR EM REAÇÕES DE ESTERIFICAÇÃO
}

\author{
Bárbara N. Aud ${ }^{a, b}$, Giovani A. Lourenço ${ }^{b}$, Lynicker Y. O. Dourado e Rosana M. N. Assunção ${ }^{\mathrm{c}, *,(1)}$ \\ anstituto de Química, Universidade Federal de Uberlândia, 38400-902 Uberlândia - MG, Brasil \\ bDepartamento de Áreas Acadêmicas, Instituto Federal de Goiás, 75523-160 Itumbiara - GO, Brasil \\ 'Instituto de Ciências Exatas e Naturais do Pontal, Universidade Federal de Uberlândia, 38304-402 Ituiutaba - MG, Brasil
}

Recebido em 13/09/2020; aceito em 10/11/2020; publicado na web em 10/12/2020

\begin{abstract}
CHEMICAL MODIFICATION OF POLYPROPYLENE THROUGH THE INTRODUCTION OF SULPHONIC GROUPS FOR APPLICATION AS CATALYST IN ESTERIFICATION REACTIONS. In this work, the chemical modification of pristine polypropylene was carried out through sulfonation reactions with concentrated sulfuric acid (PPS1) and fuming sulfuric acid (PPS2), for production of heterogeneous catalysts used in esterification reactions. Fourier transform infrared spectroscopy, elemental analysis, degree of substitution and ion exchange capacity showed that both sulfonation agents were effective to promote the functionalization of polypropylene, with the fuming sulfuric acid capable of promoting a greater chemical modification. The materials catalytic activity in esterification reaction of oleic acid with methanol was evaluated at $100{ }^{\circ} \mathrm{C}$, methanol: oleic acid molar ratio of $78: 1$ and with $5 \mathrm{wt} \%$ of catalyst (referred to oleic acid weight). It was observed that reaction catalyzed by PPS1 converted $68.02 \%$ of oleic acid to methyl oleate in 3 hours of reaction, while PPS2 reached $86.47 \%$ conversion in five hours, showing even greater catalytic efficiency than the commercial ion exchange resin, Amberlyst 15. Therefore, the conditions employed for the sulfonation of polypropylene were satisfactory to produce materials with acid characteristics necessary to catalyze the esterification reaction of oleic acid with methanol.
\end{abstract}

Keywords: sulphonated polypropylene; heterogeneous catalysis; esterification; oleic acid.

\section{INTRODUÇÃO}

O polipropileno, de fórmula molecular $\left(\mathrm{C}_{3} \mathrm{H}_{6}\right)_{\mathrm{n}}$, é um termoplástico polimerizado a partir do gás propeno sendo, ao lado do polietileno, umas das poliolefinas mais relevantes existentes no mercado. Possui um bom balanço de propriedades elétricas, químicas, mecânicas e térmicas ${ }^{1,2}$ e apresenta usos potenciais para a produção de embalagens, tubos, tanques de armazenamento, tampas de revestimento, monofilamentos, cordas, brinquedos e também outros bens duráveis. ${ }^{1,3}$ No entanto, devido a hidrofobicidade a sua química de superfície nem sempre é ideal. Em muitos casos práticos é desejável melhor aderência, molhabilidade ou biocompatibilidade, e tais propriedades só podem ser conferidas a essas superfícies por um passo de modificação superficial pós-polimerização. ${ }^{4}$

O desenvolvimento de tecnologia relacionada a funcionalização superficial de polímeros tem recebido grande atenção devido sua relevância do ponto de vista da produção de uma variedade de materiais com novas funções. ${ }^{5,6}$ Matrizes que são tipicamente hidrofóbicas e praticamente inertes passam a apresentar superfícies hidrofílicas dependendo do grupo químico introduzido. Várias técnicas têm sido empregadas na modificação de polímeros, como por exemplo: tratamentos com descargas elétricas, reações químicas, deposição e incorporação de metais, irradiação da superfície e tratamento térmico. ${ }^{7}$ Dentre as técnicas empregadas, as reações químicas estão entre os processos mais comuns sendo a sulfonação um dos procedimentos mais usados e de maior eficiência. Um dos aspectos importantes relativo a sulfonação é a possibilidade de produção de membranas e resinas sulfônicas, que podem ser empregadas em dispositivos eletrônicos como separadores em baterias, ${ }^{8}$ na terapia de hemodiálise ${ }^{9}$ e como catalisadores ácidos sólidos para diversas reações orgânicas, incluindo as utilizadas para a produção de biodiesel. ${ }^{10}$

*e-mail: rosana.assuncao@ufu.br
O biodiesel é um biocombustível definido com uma mistura de ésteres monoalquílicos oriundos de ácidos graxos de cadeias longas, que pode ser obtido através de reações de transesterificação e/ou esterificação via catálise homogênea ou heterogênea, básica ou ácida, além de poder ser produzido também por meio da catálise enzimática. Industrialmente é produzido através da reação de transesterificação utilizando-se catalisadores homogêneos alcalinos, que apresentam como fatores relevantes para sua escolha os altos valores de conversão e velocidade de formação dos produtos esperados. ${ }^{11}$ Apesar dessas vantagens, essa rota apresenta algumas desvantagens que precisam ser superadas para o emprego do processo de forma mais eficiente e competitiva comercialmente com outras fontes de combustíveis. Entre as principais desvantagens desse processo destacam-se a impossibilidade de reuso do catalisador, geração de efluentes e dificuldade de empregá-lo em matérias-primas que possuem elevada acidez e umidade, uma vez que esses materiais podem formar emulsões que dificultam a separação dos produtos e ainda produzir subprodutos indesejados como o sabão. ${ }^{12}$ Diante disso, inúmeros estudos têm sido realizados para mostrar que a substituição dos catalisadores homogêneos alcalinos por sólidos ácidos pode trazer grandes benefícios produtivos para as indústrias de biocombustíveis. ${ }^{13}$ Nesse sentido é fundamental o desenvolvimento de novos catalisadores heterogêneos que não apenas possuam boa atividade catalítica e alta estabilidade, mas também sejam baratos e possam ser facilmente sintetizados. Catalisadores poliméricos, como resinas de troca iônica, têm sido citados como catalisadores promissores em reações de esterificação. ${ }^{14,15}$ A reação de esterificação de ácidos carboxílicos de cadeia longa, como o ácido oleico, é interessante no contexto da produção de biodiesel, porque este e outros ácidos graxos livres (AGL) podem estar presentes em diferentes quantidades nas reações de transesterificação de óleos vegetais, bem como em matérias-primas recicladas.

Considerando esses aspectos, neste trabalho o polipropileno foi quimicamente modificado através de reações com ácido sulfúrico 
concentrado e fumegante, para a produção de catalisadores heterogêneos sulfonados que viabilizassem a síntese de biodiesel através da reação de esterificação do ácido oleico com metanol. Para comparação da eficiência catalítica dos materiais desenvolvidos utilizou-se a resina de troca iônica ácida, disponível comercialmente, Amberlyst 15 (uma resina macroreticular PS-DVB- $\mathrm{SO}_{3} \mathrm{H}$ ) e realizouse também a reação de esterificação sem adição de catalisador.

\section{PARTE EXPERIMENTAL}

\section{Sulfonação do polipropileno (PP)}

A sulfonação do polipropileno, que possui partículas na faixa de tamanho de 11,25 a 1002,37 um e diâmetro médio de Sauter de $194,1 \mu \mathrm{m}$, foi realizada a partir de dois planejamentos experimentais em três níveis com dois fatores $\left(3^{2}\right)$. Cada planejamento foi executado utilizando um agente de sulfonação, sendo o ácido sulfúrico concentrado $(95-99 \% \mathrm{~m} / \mathrm{m})$ e o ácido sulfúrico fumegante, $65 \%$ de grupos $\mathrm{SO}_{3}$ livres, os reagentes empregados. A metodologia e condições experimentais foram adaptadas da literatura ${ }^{4,16-20}$ e os resultados obtidos tratados com auxílio do software Statistica 7.0. A resposta estudada correspondeu à determinação da capacidade de troca iônica do polipropileno sulfonado (PPS), haja vista que além de ser um indicativo da modificação química do polímero, é também uma medida do teor de grupos ácidos acessíveis em solução e influencia diretamente na eficiência catalítica do material. As variáveis independentes e os níveis dos fatores estudados para a síntese do PPS encontram-se na Tabela 1.

Para a síntese do polipropileno sulfonado com ácido sulfúrico concentrado (PPS1), um grama de PP triturado foi imerso no ácido e mantido a $120{ }^{\circ} \mathrm{C}$ sob agitação magnética. Ao final da reação, a amostra foi lavada em quatro etapas com soluções aquosas de $\mathrm{H}_{2} \mathrm{SO}_{4}{ }^{17}$ e o processo foi finalizado em água destilada pura, com sucessivas lavagens e filtração, até que o $\mathrm{pH}$ neutro fosse atingido. Em seguida o material sulfonado foi seco em estufa à $100{ }^{\circ} \mathrm{C}$ por 12 horas. Para a produção do PPS2, polipropileno sulfonado com ácido sulfúrico fumegante, adicionou-se lentamente o agente de sulfonação sobre um grama do polipropileno e o sistema foi mantido à temperatura ambiente. Ao final do processo, a amostra foi lavada e seca conforme procedimento descrito para o PPS1. O volume de cada um dos agentes de sulfonação adicionado ao PP e os tempos de reação foram modificados de acordo com o ensaio do planejamento realizado (Tabela 2).

\section{Espectroscopia de absorção na região do infravermelho por transformada de fourier (FTIR)}

Os espectros de absorção na região do infravermelho foram obtidos em espectrofotômetro da marca Perkin Elmer, Modelo FT-IR Frontier Single Range - MIR, com cristal diamante de ATR (do inglês "Attenuated Total Reflectance"). Os dados foram obtidos com resolução de $4 \mathrm{~cm}^{-1}, 32$ acumulações no intervalo de $4000 \mathrm{~cm}^{-1}$ a $400 \mathrm{~cm}^{-1}$.

\section{Análise elementar (AE)}

As composições elementares das amostras de polipropileno puro e sulfonados foram determinadas em um analisador elementar Perkin Elmer (Série II CHNS / S - 2400). As análises foram realizadas utilizando aproximadamente $1 \mathrm{mg}$ de amostras, pesadas em uma microbalança acoplada ao aparelho, utilizando o padrão Cistina $(\% \mathrm{C}=29,98 ; \% \mathrm{H}=5,56 ; \% \mathrm{~N}=11,73 ; \% \mathrm{~S}=26,61)$.

\section{Grau de sulfonação (GS)}

O grau de sulfonação dos polímeros foi determinado através dos resultados obtidos pela análise elementar, das massas molares dos átomos constituintes e da definição da fórmula mínima das amostras modificadas. O cálculo utilizado para essa estimativa foi adaptado de trabalhos da literatura. 5,21

\section{Microscopia eletrônica de varredura (MEV)}

As imagens de MEV foram realizadas em um Microscópio Eletrônico de Varredura modelo VEGA3, TESCAN, operando a 10 $\mathrm{kV}$. As amostras foram montadas em um suporte com fita de carbono dupla face e colocadas sobre uma película de papel alumínio, para em seguida serem metalizadas com uma fina camada de ouro em uma metalizadora para carbono e ouro modelo Quorum QR 150ES.

\section{Capacidade de troca iônica (CTI)}

A capacidade de troca iônica foi determinada por titulação ácido-base, conforme procedimento adaptado da literatura. ${ }^{22,23}$ Aproximadamente $0,1500 \mathrm{~g}$ de polímero foram adicionados em um erlenmeyer contendo $20 \mathrm{~mL}$ de uma solução de $\mathrm{NaCl}\left(1,00 \mathrm{~mol} \mathrm{~L}^{-1}\right)$. A mistura foi agitada durante 24 horas e após esse tempo filtrada. O filtrado foi titulado, em triplicata, com uma solução previamente padronizada de $\mathrm{NaOH}\left(0,0485 \mathrm{~mol} \mathrm{~L}^{-1}\right)$, utilizando o indicador fenolftaleína. Após a titulação, a CTI foi calculada pelo número de miliequivalentes de $\mathrm{H}^{+}$trocados a partir da Equação 1:

$$
C T I=\frac{\mathrm{M}_{\mathrm{NaOH}} \times \mathrm{V}_{\mathrm{NaOH}}}{m p s}
$$

em que $\mathrm{M}_{\mathrm{NaOH}}$ é a molaridade da solução de $\mathrm{NaOH}\left(\mathrm{mol} \mathrm{L}^{-1}\right) ; \mathrm{V}_{\mathrm{NaOH}}$ é o volume gasto da solução de $\mathrm{NaOH}$ para neutralizar a solução ácida $(\mathrm{mL})$ e mps é a massa de polímero seco $(\mathrm{g})$.

\section{Calorimetria exploratória diferencial (DSC)}

As propriedades térmicas das amostras foram analisadas por Calorimetria Exploratória Diferencial através do emprego de um equipamento da TA Instruments, modelo DSC-25. Foram utilizados porta amostras padrão de alumínio com tampa, em que aproximadamente $6 \mathrm{mg}$ de material foram analisados na taxa de aquecimento de $10{ }^{\circ} \mathrm{C} \min ^{-1}$, de -90 a $220^{\circ} \mathrm{C}$, em atmosfera inerte de

Tabela 1. Variáveis independentes e os níveis dos fatores do planejamento na síntese do PPS

\begin{tabular}{llccc}
\hline \multirow{2}{*}{ Agente de sulfonação } & Variáveis independentes & \multicolumn{2}{c}{ Níveis } \\
\cline { 3 - 5 } & & Inferior $(-1)$ & Intermediário $(0)$ & Superior $(+1)$ \\
\hline \multirow{2}{*}{ Ácido sulfúrico concentrado } & Tempo $(\mathrm{t}, \mathrm{min})$ & 30 & 195 & 360 \\
& Volume de ácido $(\mathrm{V}, \mathrm{mL})$ & 5 & 30 & 35 \\
\hline \multirow{2}{*}{ Ácido sulfúrico fumegante } & Tempo $(\mathrm{t}, \mathrm{min})$ & 5 & 30 & 55 \\
& Volume de ácido $(\mathrm{V}, \mathrm{mL})$ & 5 & 10 & 15 \\
\hline
\end{tabular}


nitrogênio com fluxo de $50 \mathrm{~cm}^{3} \mathrm{~min}^{-1}$. A porcentagem de cristalinidade foi calculada para cada amostra e está relacionada à variação de entalpia de fusão do polímero $\left(\Delta \mathrm{H}_{\mathrm{f}}\right)$, obtida experimentalmente por DSC, e a variação de entalpia de fusão do polímero considerado $100 \%$ cristalino $\left(\Delta \mathrm{H}_{\mathrm{f}}{ }^{\circ}\right)$, conforme representado pela Equação 2. Para o PP considerado $100 \%$ cristalino $^{2}$ tem-se que $\Delta \mathrm{H}_{\mathrm{f}}^{\circ}=207 \mathrm{~J} \mathrm{~g}^{-1}$.

$$
\% \text { cristalinidade }=\frac{\Delta H_{f}}{\Delta H_{f}^{\circ}} \times 100
$$

\section{Análise termogravimétrica (TGA)}

Os ensaios de TGA das amostras pura e modificadas foram realizados em um Analisador Termogravimétrico, modelo TGA 55 da TA Instruments. Em cada ensaio, cerca de $6 \mathrm{mg}$ do material foram aquecidos em porta amostra de platina de alta temperatura (Pt-HT) de 30 até $600{ }^{\circ} \mathrm{C}$, na razão de aquecimento de $10^{\circ} \mathrm{C} \mathrm{min}^{-1}$, sob atmosfera de nitrogênio em fluxo de $60 \mathrm{~cm}^{3} \mathrm{~min}^{-1}$.

\section{Testes catalíticos}

Reação de conversão do ácido oleico em oleato de metila utilizando PPS1 e PPS2 como catalisadores

As reações de esterificação do ácido oleico com metanol foram realizadas em um balão de vidro de $250 \mathrm{~mL}$, equipado com um condensador para refluxo de metanol, um agitador magnético e um banho de óleo para garantir a temperatura da reação. As condições reacionais empregadas foram adaptadas de trabalhos anteriores ${ }^{7,15,24}$ e nesse estudo o ácido oleico, catalisador (proporção mássica em relação ao ácido oleico de 5\%) e metanol (razão molar álcool: ácido oleico de 78:1) foram vertidos sequencialmente no balão à $100{ }^{\circ} \mathrm{C}$ e a mistura trifásica foi então vigorosamente agitada durante todo o processo de esterificação sob pressão atmosférica. Após o término da reação, em tempos que variaram de 0,5 a 7 horas, o catalisador heterogêneo foi mecanicamente separado dos produtos líquidos por filtração simples e o excesso de metanol e água foram removidos da fase líquida em um evaporador rotativo.

Para comparar a atividade catalítica dos materiais produzidos e avaliar o real desempenho de cada catalisador, duas novas reações de esterificação foram realizadas nas mesmas condições experimentais descritas para PPS1 e PPS2 no tempo de cinco horas. Em uma delas a resina comercial Amberlyst 15 foi empregada como catalisador e na outra nenhum catalisador foi adicionado à mistura reacional.

\section{Índice de acidez (IA)}

A variação do índice de acidez foi determinada através de um procedimento de titulação baseado no método Ca 5a-40 da American Oil Chemist's Society ${ }^{25}$ e adaptado de trabalhos da literatura. ${ }^{26,27}$ Para o ensaio, realizado em triplicata, foram pesados aproximadamente $2 \mathrm{~g}$ de amostra em um erlenmeyer de $125 \mathrm{~mL}$ e em seguida, adicionouse $25 \mathrm{~mL}$ de uma solução neutra éter:etanol (2:1) e 3 gotas de fenolftaleína. Esta mistura foi homogeneizada e titulada com uma solução aquosa de $\mathrm{KOH}\left(0,105 \mathrm{~mol} \mathrm{~L}^{-1}\right)$, previamente padronizada, até o ponto de viragem do indicador. $\mathrm{O}$ volume gasto foi anotado e o IA calculado através da Equação 3. O ácido oleico puro foi tomado como padrão e seu índice de acidez foi calculado através da titulação também em triplicata.

$$
I A=\frac{\mathrm{M}_{\mathrm{KOH}} \times \mathrm{V}_{\mathrm{KOH}} \times \mathrm{MM}_{\mathrm{KOH}}}{m \text { amosta }}
$$

em que m amostra é a massa de óleo analisado $(\mathrm{g}) ; \mathrm{M}_{\mathrm{KOH}}$ é a molaridade da solução de $\mathrm{KOH}\left(\mathrm{mol} \mathrm{L}^{-1}\right)$; $\mathrm{V}_{\mathrm{KOH}}$ é o volume de $\mathrm{KOH}$ gasto na titulação $(\mathrm{mL})$ e $\mathrm{MM}_{\mathrm{KOH}}$ é a massa molar de $\mathrm{KOH}\left(\mathrm{g} \mathrm{mol}^{-1}\right)$.

Em seguida a conversão da reação foi determinada a partir da Equação 4:

$$
C(\%)=\frac{\mathrm{IA}_{\mathrm{i}}-\mathrm{IA}_{\mathrm{f}}}{\mathrm{IA}_{\mathrm{i}}} \times 100
$$

sendo que o subscrito " $i$ ” se refere ao valor de índice de acidez inicial, correspondente ao ácido oleico puro, e o subscrito " $\mathrm{f}$ " se refere ao índice de acidez do produto da reação de esterificação.

\section{Ensaios de reuso}

A recuperação e o decréscimo da atividade catalítica ao longo de quatro ciclos consecutivos de reação foram analisados para as amostras de polipropileno sulfonado. Antes de ser reutilizado o catalisador foi lavado com quatro alíquotas de $10 \mathrm{~mL}$ de etanol anidro, sob agitação magnética suave, para remover as impurezas na superfície ${ }^{28}$ e finalmente seco em estufa a $100{ }^{\circ} \mathrm{C}$ por 12 horas. Em seguida, a quantidade dos reagentes da reação de esterificação foi ajustada para manter a razão molar de metanol: ácido oleico em 78:1, com $5 \%(\mathrm{~m} / \mathrm{m})$ de catalisador. A reação de esterificação procedeu conforme relatado anteriormente por um período de 5 horas. As razões de uma possível desativação dos catalisadores foram investigadas através de medidas da CTI e pela determinação do percentual de enxofre via análise elementar.

\section{RESULTADOS E DISCUSSÃO}

\section{Sulfonação do polipropileno}

As condições experimentais e os resultados obtidos referentes às reações de sulfonação do $\mathrm{PP}$ executadas no planejamento fatorial de experimentos $3^{2}$, com os dois agentes de sulfonação empregados, estão apresentados na Tabela 2.

Considerando os resultados obtidos para o PPS1, apresentados na Tabela 2, pode-se observar que a CTI praticamente não se modifica com o aumento da quantidade de ácido sulfúrico adicionada para o tempo de 30 minutos de reação, indicando que este tempo é insuficiente para sulfonar eficientemente o polipropileno. Os resultados indicaram também que, para os tempos de 195 e 360 minutos de reação, os maiores valores de CTI foram obtidos quando utilizou-se volumes intermediários do ácido, visto que grandes volumes podem provocar dessulfonação parcial (hidrólise do grupo $-\mathrm{HSO}_{3}$ ), decorrente da alta concentração de íons $\mathrm{H}^{+}$e formação de água, ${ }^{29}$ reduzindo assim a CTI do polímero. Ademais, foi constatado que o aumento do tempo de reação, para os três volumes testados, aumentou a CTI do PPS1, tornando a sulfonação mais efetiva. A melhor condição experimental desse planejamento, que resultou em uma CTI de 0,7211 meq g $^{-1}$, foi de 360 minutos de reação com $20 \mathrm{~mL}$ de ácido sulfúrico concentrado adicionado ao polímero puro.

Para previsão da CTI do PPS1 produzido foi proposta uma correlação baseada nos resultados experimentais do planejamento apresentado na Tabela 2. A Equação 5 apresenta o modelo reduzido (correlação) obtido com coeficiente de determinação $\left(\mathrm{R}^{2}\right)$ de $89,1 \%$.

$$
\text { CTI }\left(m_{e q} g^{-1}\right)=0,461-0,1619 X_{2}^{2}+0,2948 X_{1}
$$

Através dessa correlação observa-se a presença de um ponto de máximo associado ao volume $\left(\mathrm{X}_{2}\right)$, haja vista a multiplicação de um coeficiente negativo $\left(\beta_{22}=-0,1619\right)$ pelo termo quadrático do volume. Somado a isso, destaca-se também que a variação da capacidade de troca iônica tem uma relação linear com o tempo e, nesse caso, como $\beta_{1}$ é positivo $(0,2948)$, conforme o tempo de reação aumenta a CTI 
Tabela 2. Matriz experimental realizada e resultados de CTI obtidos a partir do planejamento fatorial 3k para as reações de sulfonação do PP

\begin{tabular}{|c|c|c|c|c|}
\hline Agente de sulfonação & Experimentos & $X_{1}($ tempo) & $X_{2}$ (volume) & CTI (meq g $\left.{ }^{-1}\right)$ \\
\hline \multirow{10}{*}{ Ácido sulfúrico concentrado } & 1 & $-1(30 \mathrm{~min})$ & $-1(5 \mathrm{~mL})$ & 0,0200 \\
\hline & 2 & $-1(30 \mathrm{~min})$ & $0(20 \mathrm{~mL})$ & 0,0209 \\
\hline & 3 & $-1(30 \mathrm{~min})$ & $+1(35 \mathrm{~mL})$ & 0,0206 \\
\hline & 4 & $0(195 \mathrm{~min})$ & $-1(5 \mathrm{~mL})$ & 0,2782 \\
\hline & 5 & 0 (195 min) & $0(20 \mathrm{~mL})$ & 0,5429 \\
\hline & 6 & $0(195 \mathrm{~min})$ & $+1(35 \mathrm{~mL})$ & 0,3671 \\
\hline & 7 & $+1(360 \mathrm{~min})$ & $-1(5 \mathrm{~mL})$ & 0,4444 \\
\hline & 8 & $+1(360 \mathrm{~min})$ & $0(20 \mathrm{~mL})$ & 0,7211 \\
\hline & 9 & $+1(360 \mathrm{~min})$ & $+1(35 \mathrm{~mL})$ & 0,6645 \\
\hline & 10 & $0(195 \mathrm{~min})$ & $0(20 \mathrm{~mL})$ & 0,5591 \\
\hline \multirow{10}{*}{ Ácido sulfúrico fumegante } & 1 & $-1(5 \mathrm{~min})$ & $-1(5 \mathrm{~mL})$ & 1,1132 \\
\hline & 2 & $-1(5 \mathrm{~min})$ & $0(10 \mathrm{~mL})$ & 1,3580 \\
\hline & 3 & $-1(5 \mathrm{~min})$ & $+1(15 \mathrm{~mL})$ & 1,2459 \\
\hline & 4 & $0(30 \mathrm{~min})$ & $-1(5 \mathrm{~mL})$ & 1,1605 \\
\hline & 5 & $0(30 \mathrm{~min})$ & $0(10 \mathrm{~mL})$ & 1,4788 \\
\hline & 6 & $0(30 \mathrm{~min})$ & $+1(15 \mathrm{~mL})$ & 1,3140 \\
\hline & 7 & $+1(55 \mathrm{~min})$ & $-1(5 \mathrm{~mL})$ & 1,3367 \\
\hline & 8 & $+1(55 \mathrm{~min})$ & $0(10 \mathrm{~mL})$ & 1,4497 \\
\hline & 9 & $+1(55 \mathrm{~min})$ & $+1(15 \mathrm{~mL})$ & 1,0130 \\
\hline & 10 & $0(30 \mathrm{~min})$ & $0(10 \mathrm{~mL})$ & 1,4888 \\
\hline
\end{tabular}

também aumenta. A técnica de superfície de resposta ("Response Surface Methodology" - RSM), elucidada na Figura 1 (a), indica a tendência dos resultados preditos através do modelo reduzido. Portanto, fica evidente que para volumes intermediários $\left(\mathrm{X}_{2}=0\right)$ e tempo de reação próximos ao limite superior do delineamento experimental $\left(X_{1}=+1\right)$ a CTI é máxima. Também é possível observar a maior influência do tempo na variação da capacidade de troca iônica. Analisando o gráfico de contorno, Figura 1 (b), observa-se que a síntese do PPS1 pode ser controlada para os intervalos de $319\left(X_{1}=0,75\right)$ a $360 \min \left(X_{1}=1\right)$ e de $12,5\left(X_{2}=-0,5\right)$ a $27,5 \mathrm{~mL}$ $\left(X_{2}=0,5\right)$, haja vista a pequena variação da capacidade de troca iônica, da ordem de 0,01 meq g $^{-1}$.

Analisando os resultados obtidos para o planejamento da síntese do PPS2, na Tabela 2, observa-se que para todos os tempo estudados, volumes intermediários de ácido sulfúrico fumegante levaram a maiores resultados de CTI, possivelmente devido a dessulfonação parcial. ${ }^{29}$ Observa-se também que para os volumes de 10 e $15 \mathrm{~mL}$ de ácido, tempos de reação de 55 minutos diminuiram a CTI em comparação ao tempo de 30 minutos, indicando que provavelmente em longos tempos reacionais parte do polímero esteja degradando.$^{30} \mathrm{~A}$ maior capacidade de troca iônica encontrada para esse planejamento foi na condição de 30 minutos de reação com $10 \mathrm{~mL}$ de ácido sulfúrico fumegante adicionado ao polímero. É importante destacar que todos os experimentos executados com o ácido sulfúrico fumegante, mesmo em condições reacionais mais brandas, resultaram em polímeros com uma CTI maior do que aqueles obtidos com o ácido sulfúrico concentrado, demonstrando que a escolha do agente de sulfonação é decisiva para a funcionalização do material.

Para previsão da CTI do PPS2 produzido foi proposta uma correlação baseada nos resultados experimentais do planejamento

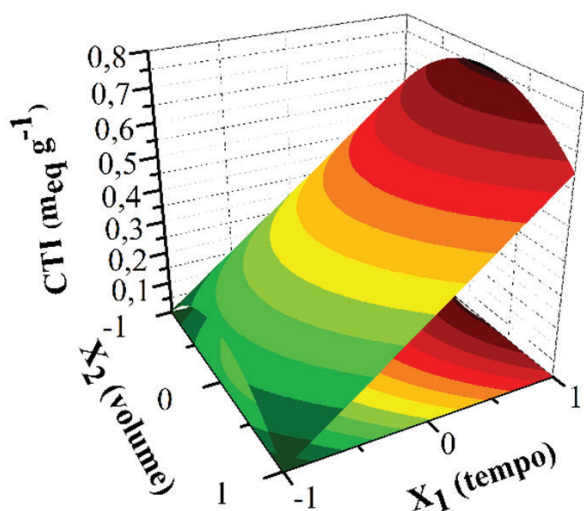

(a)

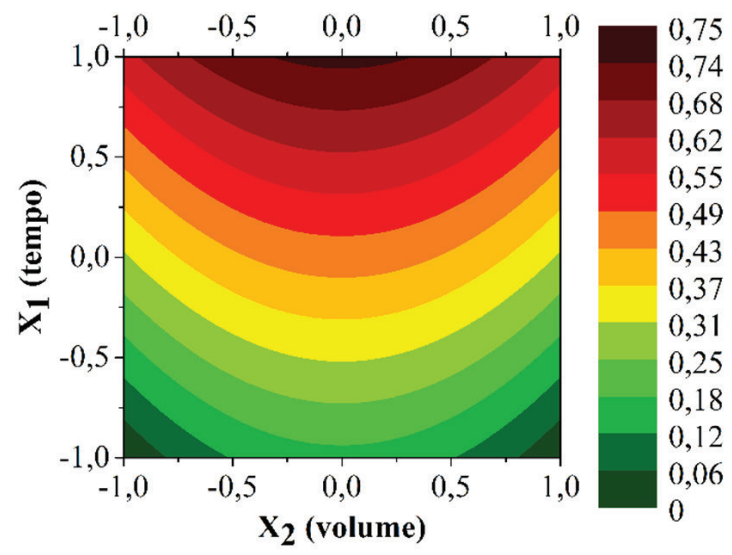

(b)

Figura 1. (a) Superfície de resposta e (b) Gráfico de contorno obtidos a partir dos resultados do planejamento experimental realizado para a síntese do PPS1 
apresentado na Tabela 2. A Equação 6 apresenta o modelo reduzido com coeficiente de determinação $\left(\mathrm{R}^{2}\right)$ de $84,4 \%$.

$$
C T I\left(m_{e q} g^{-1}\right)=1,4438-0,2466 X_{2}^{2}-0,1141 X_{1} X_{2}
$$

A partir dessa correlação observa-se, assim como na obtida para o PPS1, a presença de um ponto de máximo relacionado ao volume $\left(\mathrm{X}_{2}\right)$, mas deve-se destacar neste caso a influência da interação do tempo com o volume de ácido $\left(\mathrm{X}_{1} \mathrm{X}_{2}\right)$ na predição da CTI do material sintetizado. A técnica de superfície de resposta, apresentada na Figura 2 (a), evidencia a influência da interação. Observa-se que para o nível inferior do volume de ácido $\left(\mathrm{X}_{2}=-1\right)$ o aumento no tempo reacional aumenta a CTI do PPS2 sintetizado, enquanto, fixando-se o nível superior do volume de ácido $\left(\mathrm{X}_{2}=1\right)$, o aumento do tempo reacional diminui a CTI. Analisando o gráfico de contorno, Figura 2 (b), observa-se que a síntese do PPS2 pode ser controlada para os intervalos de $40\left(\mathrm{X}_{1}=0,4\right)$ a $55 \mathrm{~min}\left(\mathrm{X}_{1}=1\right)$ e de $8\left(\mathrm{X}_{2}=-0,4\right)$ a $10 \mathrm{~mL}\left(\mathrm{X}_{2}=0\right)$.

\section{Caracterização do polipropileno sulfonado}

As caracterizações descritas a seguir foram realizadas com o PPS1 produzido pelo experimento 8 e com o PPS2 sintetizado através do experimento 10 , ambos mostrados na Tabela 2 , visto que esses materiais sulfonados apresentaram a melhor resposta em cada um dos planejamentos experimentais executados, e também com o polipropileno puro (PP) para efeito de comparação e comprovação da modificação química.
Espectroscopia de Absorção na Região do Infravermelho por Transformada de Fourier (FTIR)

A técnica de FTIR é eficiente na identificação dos grupos funcionais e das novas ligações formadas e foi utilizada neste trabalho de forma qualitativa para avaliar a sulfonação do polipropileno. Na Figura 3 os espectros de FTIR do polímero antes e após as modificações químicas são comparados.

As bandas características do polipropileno estão presentes nos três espectros apresentados na Figura 3 (a). Dentre elas, destacase a banda que aparece na região de $2700-3000 \mathrm{~cm}^{-1}$ devido ao estiramento $\mathrm{C}-\mathrm{H}$ de grupos $-\mathrm{CH}-,-\mathrm{CH}_{2}-\mathrm{e}-\mathrm{CH}_{3}$, que permanece presente mesmo após a reação com os agentes sulfonantes, sugerindo que o ácido reage apenas com uma parte do $\mathrm{PP}^{18} \mathrm{Na}$ região entre 3700-3000 $\mathrm{cm}^{-1}$ ocorre o aparecimento de uma banda forte e larga, para as amostras de PPS, atribuída ao estiramento da ligação $\mathrm{O}-\mathrm{H}$ de água adsorvida e possivelmente do grupo sulfônico $\left(-\mathrm{SO}_{3} \mathrm{H}\right){ }^{31,32}$ Como as principais mudanças advindas do processo de sulfonação se concentram na região de 400 a $1850 \mathrm{~cm}^{-1}$, a mesma foi ampliada, conforme apresentado na Figura 3 (b), para uma melhor discussão. De acordo com a literatura, existem algumas absorbâncias típicas para os grupos sulfônicos ${ }^{8,9,16,33}$ Nos espectros apresentados para o PPS1 e PPS2, observam-se bandas em aproximadamente $1161 \mathrm{~cm}^{-1}$ e $1030 \mathrm{~cm}^{-1}$ que correspondem ao estiramento assimétrico e simétrico do $\mathrm{SO}_{3}^{-}$, respectivamente, e em $580 \mathrm{~cm}^{-1}$ uma banda atribuída ao estiramento $\mathrm{O}=\mathrm{S}=\mathrm{O}$ ou à deformação $\mathrm{C}-\mathrm{S}$. Esses aspectos indicam a modificação química do polímero e o sucesso da sulfonação utilizando tanto o ácido sulfúrico concentrado a quente como o ácido

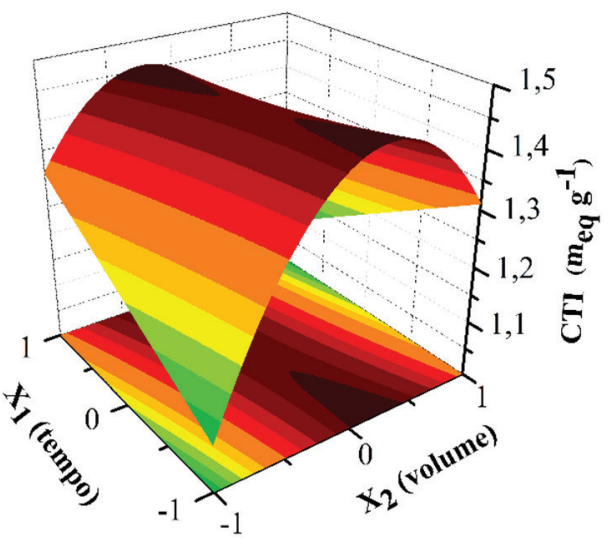

(a)

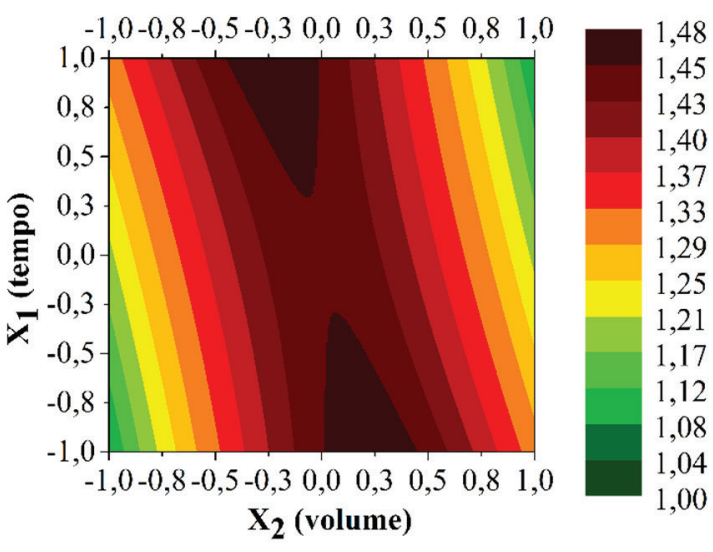

(b)

Figura 2. (a) Superfície de resposta e (b) Gráfico de contorno obtidos a partir dos resultados do planejamento experimental realizado para a síntese do PPS2

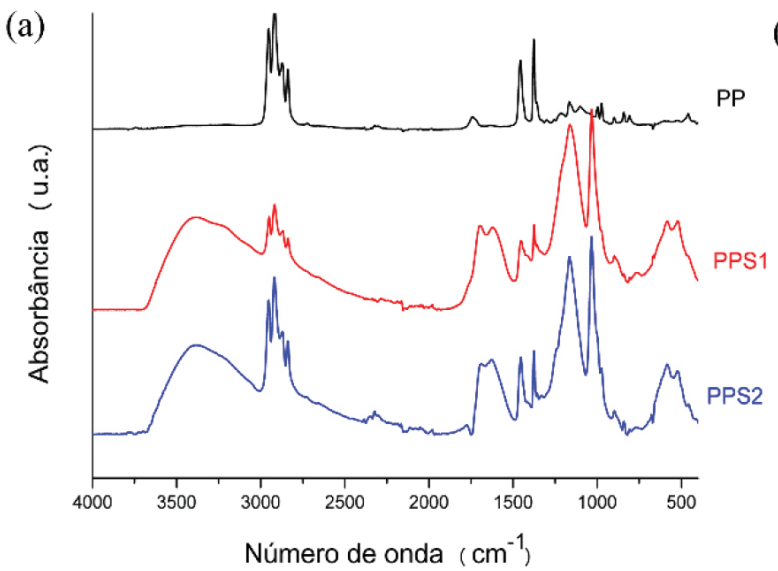

(b)

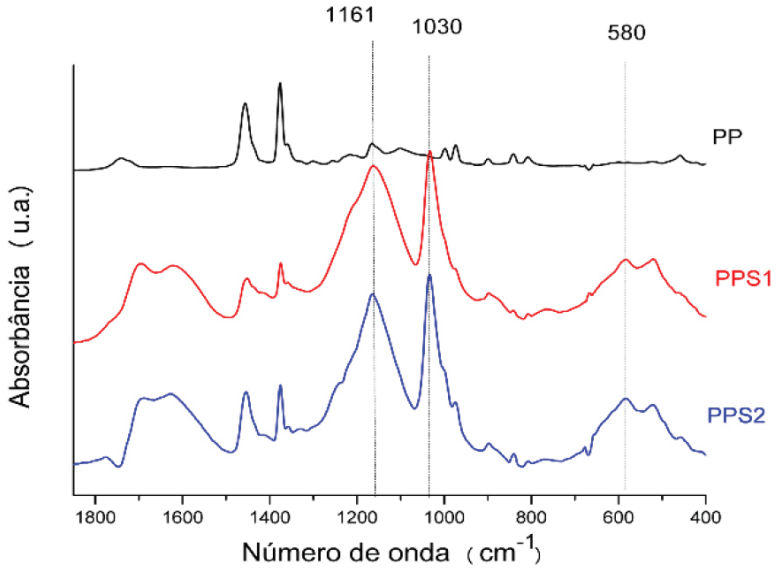

Figura 3. Espectro de infravermelho das amostras de PP, PPS1 e PPS2, na região entre 4000 a $400 \mathrm{~cm}^{-1}$ (a) e ampliação do espectro na região de 400 a $1850 \mathrm{~cm}^{-1}(b)$ 
sulfúrico fumegante à temperatura ambiente. Esses espectros também revelam o aparecimento de bandas de absorção muito característica no intervalo de 1750 a $1600 \mathrm{~cm}^{-1}$. A banda no número de onda mais alto pode ser atribuída a grupos carbonila, como cetonas, aldeídos e ácidos carboxílicos devido ao fato da sulfonação ser acompanhada pela oxidação do polímero para produzir tais grupos. ${ }^{16} \mathrm{~A}$ banda em torno de $1600 \mathrm{~cm}^{-1}$ pode ser atribuída às ligações $\mathrm{C}=\mathrm{C}$ criadas no processo de sulfonação e que que explicam as alterações de cor que ocorrem na superfície do PP com o progresso da reação. ${ }^{16}$

\section{Análise Elementar}

A sulfonação do polipropileno foi confirmada através dos dados de composição química obtidos por análise elementar, mostrados na Tabela 3, corroborando os dados observados nos espectros na região do infravermelho. Os teores de carbono $(\mathrm{C})$, hidrogénio $(\mathrm{H})$ e enxofre $(S)$ foram obtidos de forma direta pela análise, enquanto o teor de oxigênio $(\mathrm{O})$ foi determinado como a diferença entre todos os teores obtidos e $100 \%$.

Tabela 3. Composição elementar determinada para as amostras de PP, PPS1 e PPS2

\begin{tabular}{ccccc}
\hline Amostras & $\mathrm{C}(\%)$ & $\mathrm{H}(\%)$ & $\mathrm{S}(\%)$ & $\mathrm{O}(\%)$ \\
\hline PP & 85,00 & 15,00 & - & - \\
PPS1 & 74,57 & 12,22 & 4,11 & 9,10 \\
PPS2 & 55,30 & 6,60 & 7,83 & 30,27 \\
\hline
\end{tabular}

Os resultados apontaram a incorporação efetiva de grupos sulfônicos à cadeia polimérica pelas duas rotas sintéticas devido a presença de enxofre e oxigênio na composição dos polímeros modificados, ${ }^{29,34}$ confirmando assim a funcionalização dos materiais. Comparando a porcentagem de enxofre das duas amostras sulfonadas, percebe-se que para o PPS2 o valor é aproximadamente 1,9 vezes maior que para o PPS1, mesmo utilizando tempo e temperatura mais amenos para a sua produção. Essa diferença pode ser atribuída à maior porcentagem de grupos $\mathrm{SO}_{3}$ livres do agente de sulfonação utilizado na síntese do PPS2, que promove uma funcionalização mais efetiva do material.

\section{Grau de Sulfonação (GS)}

O grau de sulfonação de um polímero pode ser representado como a porcentagem de grupos sulfônicos que foram ligados às unidades monoméricas do material. Neste trabalho, o grau de sulfonação dos polímeros modificados foi estimado com base na premissa de que todo o enxofre presente no polímero está nos grupos de ácido sulfônico. ${ }^{34}$ Para o PPS1, o resultado indicou que existe um grupo sulfônico para cada 16 unidades monoméricas de polipropileno, ou seja, um grau de sulfonação de 6,30\%. Já para o PPS2, a estimativa foi de que existe um grupo sulfônico para cada 6 unidades monoméricas do PP, ou seja, um grau de sulfonação de $16,67 \%$. Como essas medidas de grau de sulfonação dependem diretamente dos resultados encontrados na análise elementar, já era esperado que o PPS2 apresentasse uma maior substituição de grupos sulfônicos nas unidades monoméricas do polímero quando comparado ao PPS1, visto que a amostra de PPS2 possui maior teor de enxofre. Devido a polaridade do grupamento sulfônico, nos casos em que o GS calculado é superior a 30\% observa-se uma elevada solubilidade dos materiais em água, portanto em virtude dos resultados encontrados para o PPS1 e PPS2, pode-se afirmar que os polímeros não são solúveis em meio polar, o que é uma característica recomendada, já que serão empregados como catalisadores ácidos heterogêneos nas reações de esterificação. ${ }^{15}$

\section{Microscopia Eletrônica de Varredura (MEV)}

As morfologias das duas amostras de polipropileno sulfonado em comparação com o polímero puro podem ser observadas nas micrografias apresentadas na Figura 4.

É possível perceber a diferença na morfologia das amostras em decorrência dos diferentes agentes de sulfonação empregados. Na Figura 4 (a) observa-se nitidamente a estrutura de um material mais denso e rígido, sem rachaduras ou cavidades. Já na superficie da amostra sulfonada com ácido sulfúrico concentrado (4 b) é possivel observar microfissuras decorrente de um processo erosivo da estrutura, promovido provavelmente pelo ataque do agente sulfonante, além de uma maior irregularidade estrutural. Na micrografia do PPS2 (4 c) é possivel observar o aparecimento de cavidades provenientes da reação e regiões bem desgastadas pelo ataque do ácido sulfúrico fumegante à superfície do $\mathrm{PP}$, indicando um processo erosivo da estrutura bem mais pronunciado. É importante ressaltar que na catálise heterogênea o aumento da área superficial é desejável para um melhor desempenho do catalisador. Embora uma medida de área superficial não tenha sido realizada, as mudanças observadas na morfologia dos materiais modificados indicam uma maior área superficial em comparação ao polímero puro.

\section{Capacidade de Troca Iônica (CTI)}

A sulfonação do polipropileno muda completamente suas características, transformando-o em um trocador de íons. A quantificação do teor de grupos sulfônicos acessíveis em solução foi realizada a partir da determinação da CTI e os resultados mostraram

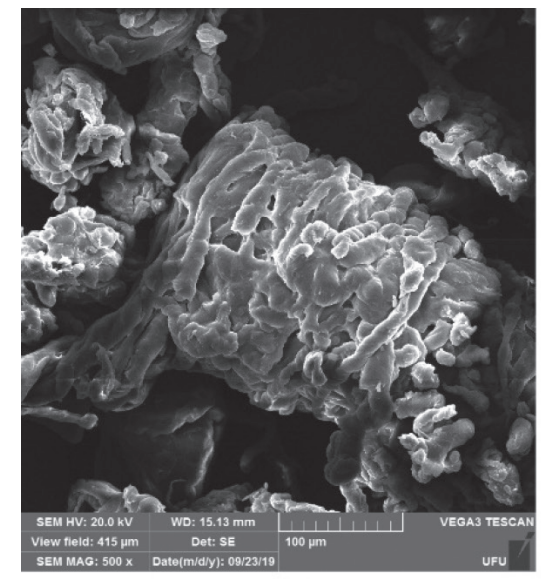

(a)

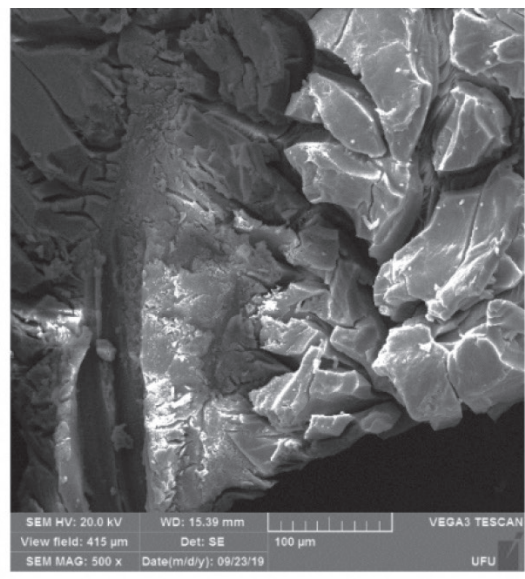

(b)

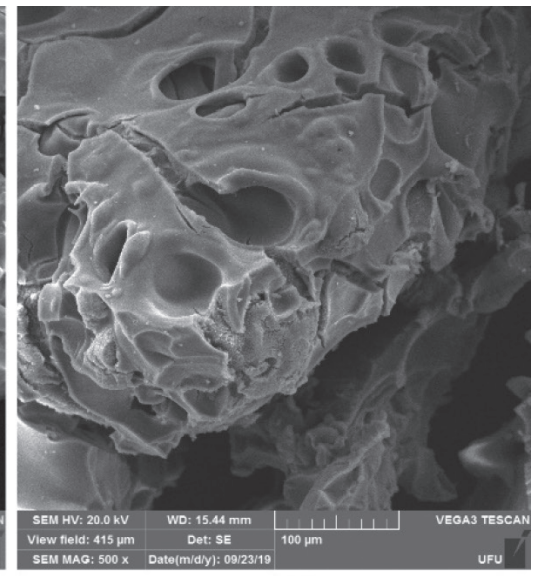

(c)

Figura 4. Microscopia eletrônica de varredura da superfície do PP (a), PPS1 (b) e do PPS2 (c) na ampliação de $500 x$ 
que o PP não apresentava nenhum grupo ionizável disponível antes da reação de sulfonação. Após modificação química com ácido sulfúrico concentrado, o polímero apresentou uma CTI de $0,7211 \mathrm{meq} \mathrm{g}^{-1} \pm 0,0130$, enquanto a síntese com o ácido fumegante produziu um material com CTI de $1,4890 \mathrm{meq} \mathrm{g-}^{1} \pm 0,0160$, indicando um aumento acentuado do teor de sítios ácidos ativos presentes no polímero. Esses resultados estão totalmente de acordo com o teor de enxofre obtido por análise elementar e com o grau de sulfonação calculado para esses dois materiais, indicando uma tendência de aumento da CTI em função do GS e do teor de enxofre para os polímeros sintetizados. Os valores de CTI obtidos encontram-se na faixa dos observados para muitos polímeros sulfonados descritos na literatura, como por exemplo, a polissulfona sulfonada sintetizada empregando o ácido clorossulfônico que apresentou CTI entre 0,53 meq $\mathrm{g}^{-1}$ e $1,19 \mathrm{meq} \mathrm{g}^{-1.35}$ o policarbonato sulfonado obtido a partir do trióxido de enxofre que apresentou um teor de grupos ácidos ionizáveis em torno de $0,58 \mathrm{meq}^{-1} ;^{36} \mathrm{o}$ polipropileno sulfonado obtido a partir da reação com ácido sulfúrico concentrado que apresentou CTI entre 0,5 e 5,3 meq $\mathrm{g}^{-1}{ }^{18}$ e o poliestireno sulfonado com diferentes agentes de sulfonação em que as capacidades de troca obtidas variaram de 0,1 a $2,2 \mathrm{meq} \mathrm{g}^{-1}$, sendo os maiores valores encontrados para a modificação realizada com o ácido clorosulfônico. ${ }^{37}$

\section{Calorimetria Exploratória Diferencial (DSC)}

Os termogramas DSC de primeira varredura para o PP, PPS1 e PPS2 são apresentados na Figura 5. Como observado, todos os materiais exibem a fusão típica do polipropileno com a reorganização de segmentos moleculares de polímero devido ao polimorfismo do PP entre $140-165^{\circ} \mathrm{C} .{ }^{19}$ Mesmo após tratamento com ácido sulfúrico concentrado a quente por 6 horas e com ácido sulfúrico fumegante, $65 \%$ de $\mathrm{SO}_{3}$ livres, o pico relacionado à fusão do polímero ainda está presente, indicando possivelmente a ocorrência de uma reação mais superficial e o ataque inicial do agente sulfonante às regiões amorfas do polímero. ${ }^{18}$ Uma modificação química mais superficial afeta positivamente a CTI do material, uma vez que torna os grupos funcionais mais disponíveis para a reação e potencializa a sua atividade catalítica. Em contrapartida, sítios ácidos mais acessíveis podem sofrer uma maior adsorção dos reagentes e produtos da reação, tornando-se bloqueados e inativos para os ciclos sucessivos, levando a necessidade de regeneração do catalisador.

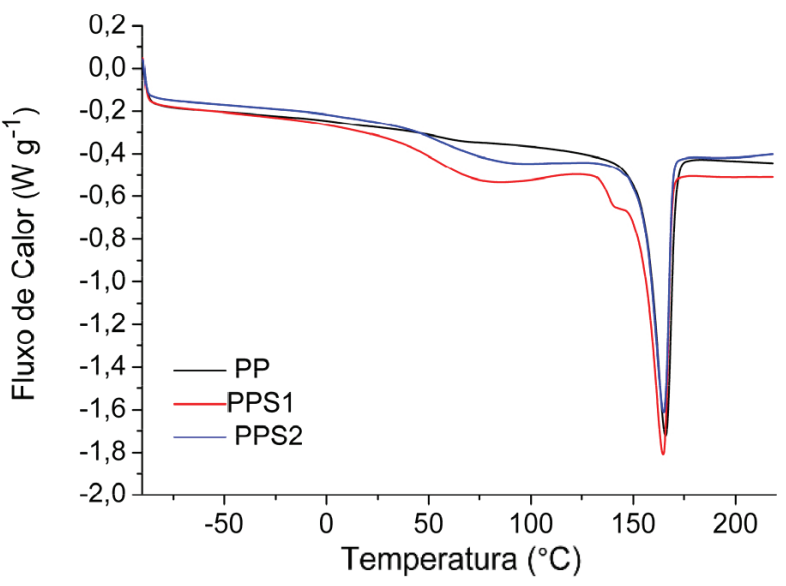

Figura 5. Curvas de DSC, primeira varredura, para o PP, PPS1 e PPS2

Além da fusão, o PPS1 e o PPS2 apresentam um outro evento de 30 a $125{ }^{\circ} \mathrm{C}$ que pode estar relacionado a volatilização da água adsorvida na estrutura dos materiais sulfonados, que não é observado para o PP puro. A Tabela 4 apresenta os valores das temperaturas de evaporação da água $\left(\mathrm{T}_{\mathrm{H}_{2} \mathrm{O}}\right)$, fusão do polímero $\left(\mathrm{T}_{\mathrm{f}}\right)$, variações de entalpia $(\Delta \mathrm{H})$ associadas a esses eventos, bem como o grau de cristalinidade $\left(\mathrm{X}_{\mathrm{c}}\right)$ calculado para cada material analisado, considerando as curvas de DSC obtidas na primeira varredura.

Tabela 4. Graus de cristalinidade, temperaturas e variações de entalpias associadas aos eventos endotérmicos presentes nas curvas de DSC, $1^{\text {a }}$ varredura, para as amostras de PP, PPS1 e PPS2

\begin{tabular}{cccccc}
\hline Amostras & $\begin{array}{c}\mathrm{T}_{\mathrm{H}_{2} \mathrm{O}} \\
\left({ }^{\circ} \mathrm{C}\right)\end{array}$ & $\begin{array}{c}\Delta \mathrm{H}_{\mathrm{H}_{2} \mathrm{O}} \\
\left(\mathrm{J} \mathrm{g}^{-1}\right)\end{array}$ & $\begin{array}{c}\mathrm{T}_{\mathrm{f}} \\
\left({ }^{\circ} \mathrm{C}\right)\end{array}$ & $\begin{array}{c}\Delta \mathrm{H}_{\mathrm{f}} \\
\left(\mathrm{J} \mathrm{g} \mathrm{g}^{-1}\right)\end{array}$ & $\begin{array}{c}\mathrm{X}_{\mathrm{c}} \\
(\%)\end{array}$ \\
\hline PP & - & - & 165,93 & 90,89 & 43,91 \\
PPS1 & 75,76 & 33,60 & 164,73 & 94,56 & 45,68 \\
PPS2 & 83,38 & 19,86 & 165,04 & 73,83 & 35,67 \\
\hline
\end{tabular}

Analisando os resultados apresentados na Tabela 4 verifica-se uma ligeira diminuição nos valores da temperatura de fusão com a sulfonação das amostras. Isso pode significar a geração de pequenos defeitos na fase cristalina como resultado da modificação química. A reação de sulfonação com o ácido sulfúrico fumegante diminuiu o grau de cristalinidade do PPS2 em relação ao PP, indicando um aumento no conteúdo da fase amorfa, ${ }^{20}$ possivelmente atribuído ao tratamento mais agressivo que esse agente de sulfonação proporciona. A redução da cristalinidade aumenta a acessibilidade do polímero, ${ }^{5}$ fato esse evidenciado pelo considerável valor de CTI encontrado para o PPS2, o que pode contribuir positivamente para o desempenho desse material como catalisador ácido heterogêneo nas reações de esterificação.

\section{Análise Termogravimétrica (TGA)}

A estabilidade térmica das amostras de polipropileno puro e modificados foram analisadas através da termogravimetria. As curvas termogravimétricas e da termogravimetria derivada (DTG) estão apresentadas na Figura 6 (a) e (b), respectivamente.

Conforme observado na Figura 6 (a), o PP permanece estável de 30 a $250{ }^{\circ} \mathrm{C}$, não havendo nessa região sinal visível de perda de massa. Essa zona de estabilidade térmica é seguida por uma rápida taxa de decomposição da cadeia polimérica, iniciada em aproximadamente $250{ }^{\circ} \mathrm{C}$, com um máximo em aproximadamente $378^{\circ} \mathrm{C}$ e finalizada em $410{ }^{\circ} \mathrm{C}$ com a decomposição completa da amostra. As curvas termogravimétricas para as amostras PPS1 e PPS 2 mostraram pequenas perdas de massa a temperaturas inferiores a $400{ }^{\circ} \mathrm{C}$, provavelmente relacionadas à evaporação da água residual dos materiais e decomposição dos grupos sulfônicos formados na reação. É interessante observar que houve um aumento significativo na temperatura de decomposição dos polímeros modificados, indicando uma alta estabilização térmica das amostras com a introdução de grupamentos sulfônicos. Além disso, é possível observar uma pequena diminuição da perda de massa com a sulfonação, indicando um aumento do resíduo carbonoso formado por decomposição térmica. O PPS1 apresentou um resíduo de 3,36\%, enquanto o PPS2 finalizou a análise com $6,59 \%$. Retenção de massa em termogramas TGA é geralmente considerada como uma medida útil da extensão da estabilização térmica. ${ }^{35} \mathrm{~A}$ formação desses resíduos carbonosos está relacionada com a presença dos grupos funcionais, ${ }^{18}$ que faz com que ocorra um aumento do grau de densidade de reticulação ${ }^{36}$ ou formação de certo grau de ligações cruzadas, ${ }^{38}$ estabilizando termicamente os materiais.

O comportamento térmico do PPS1 e PPS2 indica que esses materiais podem ser aplicados como catalisadores heterogêneos ácidos nas reações de esterificação realizadas nesse trabalho à $100{ }^{\circ} \mathrm{C}$, mostrando que não há degradação da matriz polimérica durante a reação. 


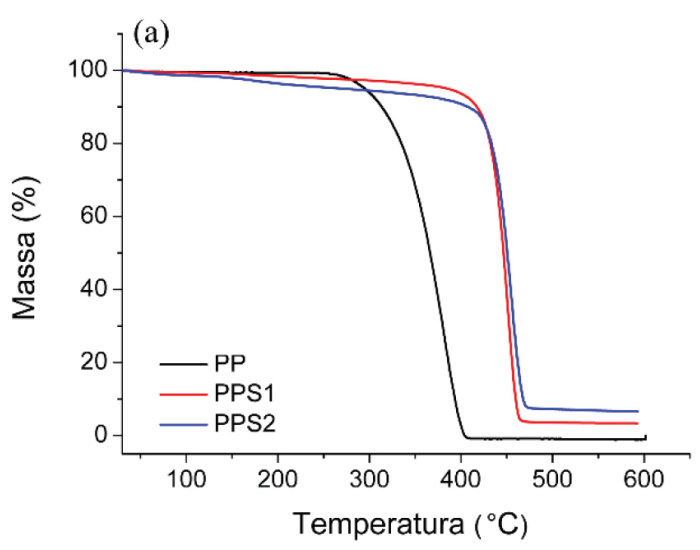

Figura 6. Curvas de TGA (a) e DTG (b) para o PP, PPS1 e PPS2

\section{Testes catalíticos}

Reação de conversão do ácido oleico em oleato de metila

As reações de esterificação requerem a adição de um catalisador para obter altas conversões e rendimentos. Como os materiais produzidos pela sulfonação do polipropileno, PPS1 e PPS2, têm acidez intrínseca de Bronsted-Lowry, eles foram testados para essa reação, uma vez que esse tipo de catalisador é o mais empregado para esse processo. ${ }^{39}$

A esterificação do ácido oleico com metanol leva a formação de oleato de metila (OM) e água. Considerando os reagentes e produtos, a ocorrência da reação pode ser acompanhada pela variação do índice de acidez, a partir da quantificação do ácido oleico residual na solução final e posterior cálculo de porcentagem da conversão da reação. ${ }^{27,28,40-42}$ A Tabela 5 apresenta os valores encontrados de conversão para as reações estudadas utilizando a determinação do IA.

Tabela 5. Análise quantitativa realizada a partir da determinação do IA dos produtos da reação

\begin{tabular}{ccc}
\hline Catalisador & Tempo de Reação (h) & Conversão em OM (\%) \\
\hline 0,5 & $11,05 \pm 0,58$ \\
1 & $24,04 \pm 0,97$ \\
PPS1 & 2 & $30,75 \pm 0,64$ \\
& 3 & $68,02 \pm 1,24$ \\
& 5 & $43,90 \pm 0,73$ \\
& 6 & $44,94 \pm 0,88$ \\
& 7 & $56,57 \pm 0,61$ \\
& 0,5 & $58,29 \pm 0,82$ \\
\hline PPS2 & 1 & $45,03 \pm 1,41$ \\
& 2 & $59,66 \pm 0,94$ \\
& 3 & $62,21 \pm 0,56$ \\
& 4 & $77,62 \pm 0,68$ \\
& 5 & $79,27 \pm 1,13$ \\
\hline Amberlyst 15 & 6 & $86,47 \pm 0,94$ \\
\hline Sem catalisador & 7 & $86,63 \pm 0,79$ \\
& 5 & $86,78 \pm 0,72$ \\
\hline & $54,14 \pm 1,07$ \\
\hline & 5 & $11,81 \pm 0,85$ \\
\hline
\end{tabular}

A análise dessas conversões mostrou que tanto o PPS1 como o PPS2 catalisaram a reação de esterificação do ácido oleico com

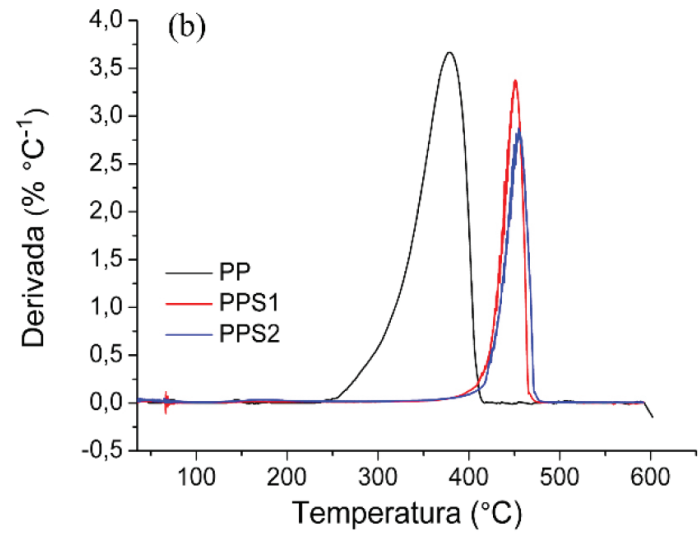

metanol, porém o PPS2 apresentou maior eficiência catalítica, atingindo uma conversão de $86,78 \%$ em 7 horas de reação. Isso pode ser atribuído aos maiores valores de grupos ácidos ionizáveis (CTI), teor de enxofre, grau de sulfonação e ao provável aumento da área superficial da amostra produzida com ácido sulfúrico fumegante, evidenciada pela análise de sua morfologia. Segundo Zong et al., ${ }^{43}$ um maior teor de grupos $-\mathrm{SO}_{3} \mathrm{H}$ representa uma maior atividade catalítica, uma vez que esse grupo é o sítio ativo do catalisador sulfonado. Isso indica que o ácido sulfúrico fumegante, $65 \%$ de $\mathrm{SO}_{3}$ livres, é um melhor agente de sulfonação para o PP, podendo ser empregado inclusive, em condições experimentais mais amenas do que o ácido sulfúrico concentrado. Takagaki et al. ${ }^{44}$ sulfonaram um carvão preparado a partir da D-glicose e também encontraram que o melhor desempenho catalítico em reações de esterificação foi com o material produzido com o ácido sulfúrico fumegante, já que o carvão produzido por essa via apresentou a maior quantidade de grupos $-\mathrm{SO}_{3} \mathrm{H}$ disponíveis para a reação, assim como o PPS2. Para esse material, os resultados obtidos mostraram que a partir de 5 horas de reação a conversão não se alterou significativamente, indicando que o equilíbrio foi atingido, não justificando assim tempos maiores que esse para a reação. Os dados da Tabela 5 também mostram que para a reação catalisada pelo PPS1, a maior conversão foi alcançada em 3 horas de reação e que após esse tempo a quantidade de biodiesel formado diminuiu. Nesse caso, tempos prolongados podem estar causando a hidrólise do éster formado, já que a reação de esterificação é um processo reversível. ${ }^{39} \mathrm{Com}$ o propósito de comparar as conversões das reações de esterificação catalisadas pelo PPS1 e PPS2, com as resultantes de um processo não catalisado e catalisado por uma resina comercial, duas novas reações foram realizadas. $\mathrm{O}$ tempo de cinco horas de reação foi escolhido para essa análise comparativa, tendo em vista que os resultados de conversão mostraram que nesse tempo a reação catalisada pelo PPS2 atingiu o equilíbrio químico com uma alta conversão. Em uma das reações, nenhum catalisador foi adicionado ao meio reacional para que fosse possível determinar a real eficiência dos materiais produzidos, e na outra uma resina de troca iônica comercial, a Amberlyst 15, foi utilizada como catalisador da reação, para comparação de seu desempenho catalítico no sistema estudado com as amostras de polipropileno sulfonado. Conforme observado na Tabela 5, uma conversão em oleato de metila de $11,81 \%$ foi encontrada para a esterificação sem adição de catalisador, indicando que a conversão da reação não catalisada é significativamente menor do que as obtidas quando utiliza-se o PPS1 e PPS2, o que evidencia o potencial catalítico dos materiais produzidos. A porcentagem de conversão encontrada quando a resina comercial Amberlyst 15 foi utilizada como catalisador da reação é $25,82 \%$ menor que a encontrada para o PPS2 no mesmo tempo, indicando que para o sistema estudado o PPS2 é um catalisador mais eficiente 
e que o seu bom desempenho não poderia ser obtido por simples substituição por produtos disponíveis no mercado, reconhecidamente utilizados como catalisadores ácidos.

O uso de catalisadores poliméricos sulfonados em reações de esterificação já é objeto de estudo na literatura. Andrijanto et al. ${ }^{45}$ empregaram o catalisador de ácido sulfônico suportado em poliestireno hiper-reticulado na reação de esterificação do ácido oleico com metanol a $65{ }^{\circ} \mathrm{C}$ e após 120 minutos de reação conseguiram uma conversão de $80 \%$. Sobreira ${ }^{7}$ utilizou o policloreto de vinila desidroclorado sulfonado na esterificação do ácido oleico com metanol a $100{ }^{\circ} \mathrm{C}$ e obteve $94 \%$ de conversão em 6 horas de reação. Pan et al. ${ }^{14}$ realizaram a reação de esterificação utilizando um catalisador ácido obtido a partir da sulfonação do etilenodiamina no polidivinilbenzeno e após 4 horas de reação a $100{ }^{\circ} \mathrm{C}$ obtiveram $85 \%$ de conversão. Para o polipropileno sulfonado, no entanto, não foram encontrados na literatura trabalhos que estudaram a sua aplicação como catalisador ácido nas reações de esterificação para a produção de ésteres alquílicos. Considerando os resultados de conversão obtidos, pode-se afirmar que o PPS2 apresentou um melhor desempenho como catalisador do processo estudado, promovendo uma conversão do ácido graxo em biodiesel de 86,47\% em 5 horas de reação. Embora a conversão utilizando o referido material seja inferior à obtida quando se utiliza o ácido sulfúrico como catalisador homogêneo (em média 99\%), há vantagens inerentes à aplicação de catalisadores heterogêneos, como a facilidade de separação, reutilização dos sólidos e diminuição dos custos com a purificação do produto. ${ }^{46}$

\section{Ensaios de reuso}

A capacidade de reutilização de uma mesma amostra de PPS1 e PPS2 foi testada, aplicando-as em quatro ciclos sequenciais de 3 horas e 5 horas cada, respectivamente. A escolha desses tempos de reação levou em consideração a máxima conversão alcançada para cada um dos catalisadores sulfonados e o fato de que para o PPS2 a reação atingiu o equilíbrio nesse tempo. Os resultados encontrados estão apresentados na Tabela 6 e mostram uma diminuição na atividade dos dois catalisadores ao longo dos ciclos.

Tabela 6. Efeito da reutilização do PPS1 e PPS2 na conversão do ácido oleico em oleato de metila

\begin{tabular}{ccc}
\hline Catalisador & Número de ciclos & Conversão em OM (\%) \\
\hline \multirow{3}{*}{ PPS1 (3h de reação) } & 1 & $68,02 \pm 1,24$ \\
& 2 & $50,78 \pm 0,39$ \\
& 3 & $43,45 \pm 0,88$ \\
& 4 & $37,71 \pm 0,76$ \\
\hline \multirow{2}{*}{ PPS2 (5h de reação) } & 1 & $86,47 \pm 0,94$ \\
& 2 & $56,34 \pm 0,32$ \\
& 3 & $47,73 \pm 0,95$ \\
& 4 & $40,58 \pm 1,27$ \\
\hline
\end{tabular}

Considerando as conversões obtidas com o reuso do PPS1, observa-se que no segundo ciclo há uma redução de $25,35 \%$ na conversão em comparação ao valor obtido no primeiro ciclo. Para os ciclos sucessivos, o decréscimo da conversão foi um pouco menor e se manteve praticamente constante, reduzindo $14,43 \%$ do ciclo 2 para o 3 e 13,21\% do terceiro para o quarto ciclo. Uma tendência de redução similar foi encontrada quando empregou-se o PPS2 como catalisador, tendo a conversão reduzido $34,84 \%$ do primeiro para o segundo ciclo, $15,28 \%$ do ciclo 2 para o 3 e $14,98 \%$ do terceiro para o quarto ciclo. Para investigar as possíveis causas dessa perda de eficiência das amostras de PPS1 e PPS2, medidas de
CTI e determinação do teor de enxofre por análise elementar foram realizadas com os catalisadores antes e após cada ciclo. A Tabela 7 apresenta esses resultados, indicando os valores de CTI e porcentagem de enxofre dos polímeros antes de serem submetidos aos ciclos que estão relacionados.

Tabela 7. Capacidade de troca iônica e teor de enxofre do PPS1 e PPS2 submetidos aos quatro ciclos sequenciais de reação

\begin{tabular}{lccc}
\hline Catalisador & Ciclo & CTI $\left(\mathrm{meq} \mathrm{g}^{-1}\right)$ & Teor de enxofre (\%) \\
\hline & 1 & $0,7211 \pm 0,0117$ & 4,11 \\
PPS1 (3h de reação) & 2 & $0,4940 \pm 0,0171$ & 2,98 \\
& 3 & $0,4124 \pm 0,0153$ & 2,31 \\
& 4 & $0,3813 \pm 0,0157$ & 1,96 \\
\hline \multirow{2}{*}{ PPS2 (5h de reação) } & 1 & $1,4890 \pm 0,0160$ & 7,83 \\
& 2 & $0,8565 \pm 0,0123$ & 5,16 \\
& 3 & $0,7064 \pm 0,0175$ & 3,77 \\
& 4 & $0,6864 \pm 0,0124$ & 3,26 \\
\hline
\end{tabular}

Os resultados da Tabela 7 evidenciam que a queda de desempenho dos catalisadores à medida que foram reciclados pode estar relacionada a inacessibilidade e consequente desativação dos grupos ativos na estrutura polimérica por bloqueio pelos reagentes e produtos da reação, a perda de grupos sulfônicos da superfície do catalisador por lixiviação ou até mesmo uma combinação desses mecanismos de desativação. ${ }^{47,48}$ Soldi et al. ${ }^{49}$ Zhu et al.,${ }^{50}$ González et al. ${ }^{51} \mathrm{e}$ Niu et al. ${ }^{28}$ encontraram uma tendência de redução semelhante para seus catalisadores sulfonados e indicaram que a perda de atividade catalítica se deve principalmente ao bloqueio dos locais funcionais durante a esterificação. A desativação do catalisador também pode ser causada pela lixiviação de sítios ácidos durante a reação, como relatado nos trabalhos de Dechakhumwat et al., ${ }^{22}$ Corrêa et al. ${ }^{41}$ Sangar et al. ${ }^{42}$ e Wang et al. ${ }^{52}$ Em muitos casos os catalisadores reciclados são submetidos à etapa de regeneração da fase ativa, anterior à sua reutilização, através de tratamentos com ácidos ou lavagens com solventes mais adequados, ${ }^{22,50,51}$ para minimizar a perda de eficiência. Neste trabalho, experimentos sucessivos foram realizados com os polímeros sem nenhuma etapa de regeneração anterior, o que pode ter contribuído para a queda do desempenho catalítico.

\section{CONCLUSÕES}

O polipropileno foi eficientemente sulfonado, com ácido sulfúrico concentrado (PPS1) e com ácido sulfúrico fumegante (PPS2), para produção de catalisadores poliméricos heterogêneos ácidos. Ambos materiais apresentaram atividade catalítica para a reação de esterificação do ácido oleico com metanol, sendo que o PPS2 apresentou melhor desempenho, atingindo uma conversão de 86,47\% em 5 horas de reação, a $100{ }^{\circ} \mathrm{C}$, com uma razão molar álcool: óleo de $78: 1$ e $5 \%(\mathrm{~m} / \mathrm{m})$ de catalisador, alcançando inclusive maior eficiência catalítica que a resina de troca iônica comercial, Amberlyst 15. Os resultados obtidos são promissores, contudo, um tratamento mais detalhado do processo de regeneração dos catalisadores precisa ser realizado, com a finalidade de melhorar o desempenho dos materiais após vários ciclos sucessivos de reação.

\section{AGRADECIMENTOS}

Os autores agradecem à Financiadora de Estudos e Projetos (Números 01.11.0135.00 e 01.13.0371.00) pelo suporte à pesquisa 
e desenvolvimento, aos Laboratórios Multiusuários do Instituto de Química, do Campus Pontal (LEMUP) e ao Laboratório de Fotoquímica e Ciências dos Materiais (LAFOT - CM) da Universidade Federal de Uberlândia por fornecer os equipamentos e apoio técnico para realização dos ensaios e ao IFG pela bolsa de estudo PIQS.

\section{REFERÊNCIAS}

1. Ghoshal, S.; Wang, P. H.; Gulgunje, P.; Verghese, N.; Kumar, S.; Polymer (Guildf) 2016, 100, 259.

2. Mhumak, C.; Pechyen, C.; Walailak J. Sci. Technol. 2018, 15, 765.

3. Tang, F.; Bao, P.; Roy, A.; Wang, Y.; Su, Z.; Polymer (Guildf) 2018, 142, 155.

4. Stakne, K., Smole, M. S., Kleinschek, K. S., Jaroschuk, A.; Ribitsch, V.; J. Mater. Sci. 2003, 38, 2167.

5. Ali, H. M. A., Silva, C. V., Royer, B., Rodrigues Filho, G., Cerqueira, D. A.; Assunção, R.; Materials 2017, 10, 1298.

6. Niu, Z., Zhao, Y., Sun, W., Shi, S.; Gong, Y.; Appl. Surf. Sci. 2016, 386, 41.

7. Sobreira, H. D. A.; Dissertação de Mestrado, Universidade Federal de Uberlândia, Brasil, 2016.

8. Wu, G. M.; Lin, S. J.; Yang, C. C.; J. Membr. Sci. 2006, 284, 120.

9. Li, R.; Cai, X. M.; Ye, Y.; Wu, G. Z.; J. Appl. Polym. Sci. 2018, 135, 1.

10. Struck, M.; Widdecke, H.; Angew. Makromol. Chemie 1996, 235, 131.

11. Zhang, Y.; Dubé, M. A.; McLean, D. D.; Kates, M.; Bioresour. Technol. 2003, 90, 229.

12. Qi, J. J.; Lin, J. Q.; Fu, H. Q.; Curr. Sci. 2016, 110, 2129.

13. Mardhiah, H. H.; Ong, H. C.; Masjuki, H. H.; Lim, S.; Lee, H. V.; Renewable Sustainable Energy Rev. 2017, 67, 1225.

14. Pan, H., Liu, X., Zhang, H., Yang, K., Huang, S.; Yang, S.; Renewable Energy 2017, 107, 245.

15. Lima, A. P., Tirone, A. V., Batista, A. C. F., Morais, L., Souza, P., Duarte, M. V. F.; Pasquini, D.; Rev. Virtual Quim. 2018, 10, 124.

16. Kaneko, M.; Sato, H.; Macromol. Chem. Phys. 2005, 206, 456.

17. Tada, H.; Ito, S.; Langmuir 1997, 13, 3982.

18. Matos, J. P.; Sansiviero, M. T. C.; Lago, R. M.; J. Appl. Polym. Sci. 2010, 115, 3586.

19. Ecevit, S. T; Aras, L.; Tinker, T.; J. Adhes. Sci. Technol. 2008, 22, 1285.

20. Karacan, I.; Benli, H.; J. Appl. Polym. Sci. 2011, 123, 3375.

21. Nascimento, B., Filho, G. R., Frigoni, E. S., Soares, H. M.; da Silva Meireles, C.; Cerqueira, D. A.; Assunção, R. M. N.; Motta, L. A. de C.; J. Appl. Polym. Sci. 2012, 124, 510.

22. Dechakhumwat, S.; Hongmanorom, P.; Thunyaratchatanon, C.; Smith, S. M.; Boonyuen, S.; Luengnaruemitchai, A.; Renewable Energy 2020, $148,897$.

23. Tang, X.; Niu, S.; Zhao, S.; Zhang, X.; Li, X.; Yu, H.; Han, K.; J. Ind. Eng. Chem. 2019, 77, 432.

24. Dourado, L. Y. O.; Dissertação de Mestrado, Universidade Federal de Uberlândia, Brasil, 2019.

25. American Oil Chemist's Society (A. O. C. S.); Oficial methods and recommended practices of the American Oil Chemist's Society (Ca 5a40), 1989
26. Colonelli, T. A.; Da Silva, C.; Semina: Ciências Exatas e Tecnológicas 2014, 35, 25.

27. Alismaeel, Z. T.; Abbas, A. S.; Albayati, T. M.; Doyle, A. M.; Fuel 2018 , 234,170

28. Niu, S.; Ning, Y.; Lu, C.; Han, K.; Yu, H.; Zhou, Y.; Energy Convers. Manage. 2018, 163, 59.

29. Kucera. F.; Jancar. J. Polym. Eng. Sci. 1998, 3, 783.

30. Cheikh, R. Ben; Askeland, P. A.; Schalek, R. L.; Drzal, L. T.; J. Adhes. Sci. Technol. 2002, 16, 1651.

31. Fatarella, E.; Mylläri, V.; Ruzzante, M.; Pogni, R.; Baratto, M. C.; Skrifvars, M.; Syrjälä, S.; Järvelä, P.; J. Appl. Polym. Sci. 2015, 132, 1.

32. Zalakain, I.; Politakos, N.; Ramos, J. A.; Saralegi, A.; Etxeberria, H.; Mondragon, I.; Corcuera, M. A.; Eceiza, A.; Eur. Polym. J. 2013, 49, 2120

33. Andrade, B. T. N. C.; Bezerra, A. C. D. S.; Calado, C. R.; Rev. Mater 2019, 24, e-12417.

34. Liu, T.; Li, Z.; Li, W.; Shi, C.; Wang, Y.; Bioresour. Technol. 2013, 133, 618.

35. Lufrano, F., Squadrito, G., Patti, A.; Passalacqua, E.; J. Appl. Polym. Sci. 2000, 77, 1250 .

36. Smitha, B., Sridhar, S.; Khan, A. A.; J. Membr. Sci. 2003, 225, 63.

37. Lee, J. H.; Kang, S. J.; Lee, Y.; Do Nam, J.; Polym. Bull. 2010, 64, 717.

38. Souza, T. D. S.; Dissertação Mestrado, Universidade Presbiteriana Mackenzie, São Paulo, Brasil, 2012.

39. Oliveira, J. F. G.; Lucena, I. L.; Saboya, R. M. A.; Rodrigues, M. L.; Torres, A. E. B.; Fernandes, F. A. N.; Parente Jr, E. J. S.; Renew. Energy 2010, 35, 2581

40. Liu, F.; Ma, X.; Li, H.; Wang, Y.; Cui, P.; Guo, M.; Yu, M.; Fuel 2020 , 266,117149 .

41. Corrêa, A. P.; Bastos, R. R. C.; da Rocha Filho, G. N.; Zamian, J. R.; da Conceição, L. R. V.; RSC Adv. 2020, 10, 20245.

42. Sangar, S. K., Lan, C. S., Razali, S. M., Farabi, M. A., Taufiq-Yap, Y. H.; Energy Convers. Manage. 2020, 196, 1306.

43. Zong, M.-H.; Duan, Z.-Q.; Lou, W.-Y.; Smith, T. J.; Hu, H.; Green Chem. 2007, 9, 434.

44. Takagaki A.; Toda, M; Okamura, M.; Kondo, J. M.; Hayashi, S.; Domen, K.; Hara, M.; Catal. Today 2006, 116, 157.

45. Andrijanto, E., Dawson, E. A.; Brown, D. R.; App. Catal., B 2012, 115, 261.

46. Saboya, R. M. A.; Dissertaçao de Mestrado.Universidade Federal do Ceará, Brasil, 2012.

47. Lee, A. F.; Wilson, K.; Catal. Today 2015, 242, 3.

48. Alcañiz-Monge, J.; Trautwein, G.; Marco-Lozar, J. P.; Appl. Catal., A 2013, 468,432

49. Soldi, R. A., Oliveira, A. R., Ramos, L. P., César-Oliveira, M. A. F.; App. Catal., A 2009, 361, 42.

50. Zhu, M., He, B., Shi, W., Feng, Y., Ding, J., Li, J.; Zeng, F.; Fuel 2010, 89, 2299.

51. González, M. E.; Cea, M.; Reyes, D.; Romero-Hermoso, L.; Hidalgo, P.; Meier, S.; Navia, R.; Energy Convers. Manage. 2017, 137, 165.

52. Wang, Y. T; Fang, Z.; Zhang, F.; Catal. Today 2019, 319, 172. 